\title{
Exposure-response relationships for annoyance due to freight and passenger railway vibration exposure in residential environments
}

 \\ and David C. Waddington \\ Acoustics Research Centre, University of Salford, Salford, M5 4WT, United Kingdom
}

(Received 25 March 2013; revised 4 November 2013; accepted 12 November 2013)

\begin{abstract}
In this work, exposure-response relationships for annoyance due to freight and passenger railway vibration exposure in residential environments are developed, so as to better understand the differences in human response to these two sources of environmental vibration. Data for this research come from a field study comprising interviews with respondents and measurements of their vibration exposure $(N=752)$. A logistic regression model is able to accurately classify $96 \%$ of these measured railway vibration signals as freight or passenger based on two signal properties that quantify the duration and low frequency content of each signal. Exposure-response relationships are then determined using ordinal probit modeling with fixed thresholds. The results indicate that people are able to distinguish between freight and passenger railway vibration, and that the annoyance response due to freight railway vibration is significantly higher than that due to passenger railway vibration, even for equal levels of

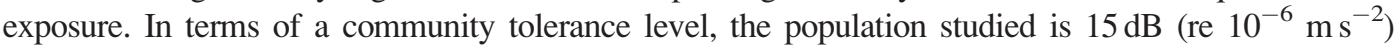
more tolerant to passenger railway vibration than freight railway vibration. These results have implications for the expansion of freight traffic on rail, or for policies to promote passenger railway.
\end{abstract}

(C) 2014 Acoustical Society of America. [http://dx.doi.org/10.1121/1.4836115]

PACS number(s): 43.40.Ng, 43.50.Qp, 43.60.Np [LMW]

Pages: 205-212

\section{INTRODUCTION}

Railway transport is generally argued to be safer, more sustainable and a more climate friendly mode of transportation when compared with road and air transport (Wiebe et al., 2011). This, in combination with the need to decrease road congestion by addressing the imbalance between transportation modes, has influenced European policy to direct movement of freight transport from the roads and onto the rails. Specifically, the International Union of Railways (UIC), the Community of European Railways (CER), the International Union of Public Transport (IUPT), and the Union of European Railway Industries (UNIFE) have agreed to achieve an increase of the market share of freight traffic on rail from $8 \%$ in 2001 to $15 \%$ in 2020 (Commission of the European Communities, 2001). This increase in freight railway transport will lead to an increase in resulting noise and vibration and the potential effects that this may have on residents living in the vicinity of railway lines needs to be understood. This paper therefore aims to develop exposureresponse relationships describing the annoyance response due to exposure to freight and passenger railway vibration.

The human response to railway vibration has been researched in several field studies. Knall (1996) summarizes the results of a German field study of 565 households in which, although it was not possible to correlate vibration intensity with annoyance, it was found that many residents living in the vicinity of railway lines consider themselves to be greatly affected by railway vibration, with $22 \%$ of the

\footnotetext{
a) Author to whom correspondence should be addressed. Electronic mail: C.Sharp@edu.salford.ac.uk
}

studied population reporting vibration disturbance to be "considerable" and $14 \%$ reporting it to be "intolerable." A Norwegian study of 1427 residents showed a correlation between vibration exposure (quantified by a statistical maximum weighted vibration velocity) and annoyance response (Klæboe et al., 2003). In a survey of five North American cities, Zapfe et al. (2009) were able to develop exposureresponse relationships demonstrating an increase in annoyance with increasing vibration exposure [quantified as a maximum root mean square (rms) vibration velocity level]. The Swedish research project Train Vibration and Noise Effects (TVANE) studied the effects of railway vibration in residential environments and developed exposure-response relationships demonstrating an increase in annoyance with increasing vibration exposure (quantified as vibration velocity) (Gidlöf-Gunnarsson et al., 2012). Further exposure-response relationships were developed from the results of a field survey carried out in England and funded by the Department for the Environment, Food and Rural Affairs (Defra), again showing an increase in annoyance response with increasing levels of railway vibration exposure (quantified either as rms acceleration or vibration dose value) (Waddington et al., 2014).

The effect of combined noise and vibration from railway sources has also been examined, with several studies showing that general annoyance reactions to railway noise increases when perceptible vibration is also present (GidlöfGunnarsson et al., 2012; Lercher, 2011; Öhrström, 1997; Schomer et al., 2012; Waddington et al., 2014) and that total annoyance caused by combined noise and vibration is considerably higher than annoyance caused by noise alone (Lee and Griffin, 2013). Indeed, Schomer et al. (2012) suggest the 
need to develop separate predictions for annoyance due to railway noise for railway sources that produce perceptible vibrations and for those that do not. They demonstrate that, even though railway noise is generally believed to be less annoying than road traffic noise (Miedema and Vos, 1998; Moehler, 1988; Moehler et al., 2000), when perceptible vibration is present, railway noise can actually cause more annoyance than road traffic noise.

Although the results of several field and laboratory studies indicate that respondents rate freight railway noise as more annoying than passenger railway noise (Andersen et al., 1983; Fields and Walker, 1982; Fields, 1979), a relatively small number of studies have addressed this difference in human response directly. In light of the imminent construction of the Betuweroute, a freight-only railway route between the Netherlands and Germany, de Jong and Miedema (1996) analyzed a number of field studies to investigate potential differences in the annoyance response caused by freight and passenger railway traffic. They concluded that residents are more likely to report annoyance due to freight railway traffic, yet no consistent differences in dose-response relationships were found when the effects of differing noise levels were removed. A laboratory study performed by Saremi et al. (2008) investigated the effects of nocturnal railway noise on sleep fragmentation and found that awakenings were produced more frequently by freight trains than automotive and passenger trains. Their results showed that, even for equal maximum noise levels and pass-by patterns during the night, sleep is more fragmented by freight trains than by passenger and automotive trains.

In a German field study, Pennig et al. (2012) investigated annoyance and self-reported sleep disturbance due to night time railway noise, with specific attention paid to differences in response to freight and passenger railway sources. They found that annoyance was primarily determined by freight trains, with annoyance ratings increasing significantly with the total number of trains and freight trains per night, but not with increasing numbers of passenger trains. The total number of trains and freight trains were also found to significantly affect the frequency of self-reported awakenings. In providing some possible explanations for the difference in annoyance response, they cite the typically longer durations of freight train pass-bys, higher maximum sounds levels, their increased occurrence during night time hours and the potential for the presence of ground-borne vibrations and accompanying low frequency noise. As part of the same study, Elmenhorst et al. (2012) investigated the difference in response between nocturnal railway noise and air traffic noise using polysomnography. It was found that nocturnal freight railway noise accounted for more awakenings than passenger railway noise and aircraft noise.

To summarize, a great deal of field and laboratory studies have focused on the human response to railway noise, yet the human response to railway vibration has been somewhat less examined. In particular, the differences in human response to freight and passenger railway noise has received less focus and studies on the difference in human response to freight and passenger railway vibration are almost nonexistent. In light of the fact that freight railway traffic is increasing, it is important that the human response to freight railway vibration be better understood. The aim of this paper, therefore, is to develop exposure-response relationships for annoyance caused by exposure to vibration from freight and passenger railway vibration, allowing the difference in response to these two sources of railway vibration to be determined. This research is an extension of the field study performed by Waddington et al. (2014) and utilizes the same measurement and response data. Freight and passenger railway vibration events are identified using logistic regression and resulting source exposures are calculated. Exposureresponse relationships for freight and passenger railway vibration are then derived using an ordinal probit model with fixed thresholds.

\section{METHODS}

\section{A. Brief summary of field study}

Data for this research come entirely from that collected during the field studies of Waddington et al. (2014). During this field study, vibration exposures were determined by measurement and human responses were determined by questionnaire. The exposure measurement protocol involved long term vibration monitoring at external control positions combined with time synchronized short term measurements performed inside residences located within $100 \mathrm{~m}$ of railway lines. The transmissibility calculated between the internal and control position measurements allowed for the estimation of $24 \mathrm{~h}$ vibration acceleration time histories within these residences. The vibration measurements were performed using Guralp CMG-5TD strong motion accelerometers with a sampling rate of $200 \mathrm{~Hz}$ and a $100 \mathrm{~Hz}$ low pass filter. As well as estimations of vibration exposures, response data were collected for each resident through the use of face-toface interviews conducted with residents in their homes. The questionnaires for these interviews were posed as a neighborhood satisfaction survey so as not to bias responses toward questions relating to noise and vibration. Among other things, the questionnaires gathered information on annoyance caused by noise and vibration from different railway sources. Exposure-response relationships were then determined from the measured exposure and collected response data using an ordinal probit model with fixed thresholds. In total, exposure-response relationships for annoyance caused by total railway vibration exposure over $24 \mathrm{~h}$ were estimated for 752 residents.

\section{B. Classification of vibration events}

\section{The logistic regression model}

In order to determine freight and passenger railway vibration exposures for each resident, the individual railway vibration events that they were exposed to must be classified as either freight or passenger. This is achieved with a logistic regression model, shown in Eq. (1). The logistic regression model is a function of several calculated signal properties or "features," $\mathbf{X}$, and associated estimated parameters, $\boldsymbol{\theta}$. The function is then fitted to labeled data by minimizing its negative $\log$ likelihood function [Eq. (2)], where $h\left(x_{m}\right)$ is the 
predicted probability (between 0 and 1) that signal $m$ belongs to the freight railway class and $y_{m}$ is the label of the class to which the signal actually belongs ( passenger $=0$, freight $=1$ ),

$$
\begin{aligned}
h(\mathbf{X}) & =\frac{1}{1+e^{-\mathbf{X} \boldsymbol{\theta}}}, \\
L(\boldsymbol{\theta}) & =\sum_{m} y_{m} \ln \left[h\left(x_{m}\right)\right]+\left[1-y_{m}\right] \ln \left[1-h\left(x_{m}\right)\right] .
\end{aligned}
$$

Labeled data for this study are available as the researchers involved in the field study noted details of train pass-bys that occurred during certain periods of internal measurements. In many cases, the researchers noted the type of train and the time associated with each pass-by on a handwritten log, allowing these known vibration event signals to be found within the continuous $24 \mathrm{~h}$ measurement data and to be subsequently extracted and labeled as freight or passenger events. In total, 194 passenger and 44 freight railway vibration signals were identified and labeled. These vibration signals were taken from 27 separate $24 \mathrm{~h}$ control position measurements spread over 7 sites in along the West Coast Main Line in the North West and Midlands regions of England.

\section{Feature selection}

Finding features that can be used to effectively differentiate between two classes not only results in an accurate classification model, but also provides information about the differences in the two classes. When optimizing the features used in the logistic regression model for this research, over 130 features were initially introduced to the model. These features included: the vibration dose value, rms acceleration, standard deviation, skewness, kurtosis, peak particle acceleration, equivalent vibration level, and the vibration event level all in three orthogonal directions (vertical, north/south and east/west). In addition, since freight railway pass-bys are typically much longer than those of passenger railway passbys, several duration descriptors were introduced, including: 10 and $3 \mathrm{~dB}$ envelopes of the signal, and the "event duration" defined here as the duration of the signal that exceeds the top third of the signal's dynamic range. Downpoints are defined as points in which the signal falls 3 and $10 \mathrm{~dB}$ below its peak value. A rise time was defined as the length of time between the first 10 and $3 \mathrm{~dB}$ downpoints and a fall time was defined as the length of time between the last 3 and $10 \mathrm{~dB}$ downpoints. Finally, since low frequency vibration energy is of interest, some frequency descriptors were introduced. The vibration energy in terms of rms acceleration and vibration dose values was determined for each $1 / 3$ rd octave band with center frequencies between 0.5 and $80 \mathrm{~Hz}$, both weighted and unweighted as per BS 6472-1 (British Standards Institution, 2008) for vibration dose value and ISO 2631-1 (International Organization for Standardization, 1997) for rms acceleration. Since the variation for total energy between each signal and for different control position measurements is high, the energies contained within each $1 / 3 \mathrm{rd}$ octave band were converted to the proportion of overall energy of the signal. Finally, due to potential differences in ground conditions and source to receiver distances between measurement positions, each signal feature was normalized against the mean value of the same features of all event signals recorded at the same control position, using the same instrument.

Using a combination of univariate and multivariate significance testing, testing of correlation between features and accuracy testing, non-significant features were removed and finally the number of features was reduced to only 2. To avoid bias when reporting the accuracy of the model, the labeled data set was split into training, cross-validation and test sets. The final two features are the event duration $(T)$ and the proportional energy in terms of the rms acceleration of the $5 \mathrm{~Hz} 1 / 3 \mathrm{rd}$ octave band $(F)$, both in the vertical direction. A likelihood ratio test of this fully reduced model against other tested models with more features suggests that the fully reduced model has no significant reduction in goodness of fit. Additionally, this model of two features results in the highest, or at least comparative, accuracy when compared with all other tested models. Reducing the model further, i.e., using only $T$ or $F$ on their own, results in a decrease of the model's accuracy and significance.

\section{The optimized logistic regression model}

The optimized logistic regression model is a function of only two features, one of which quantifies the duration of the event, $(T)$, with the other quantifying its low frequency energy $(F)$. Using only these two features, the logistic regression model is able to correctly classify, on average, $96 \%$ of all signals tested, with a precision of $91 \%$ and a recall of $88 \%$. As a final check, 500 random vibration signals were visually inspected by the authors of this paper, who made the same decisions as the logistic regression model for $94 \%$ of the vibration signals inspected. Details of the logistic regression model are presented in Table I. Figure 1 shows all of the labeled vibration signals plotted in the twodimensional feature space of $T$ and $F$. Also shown is the decision boundary for which $h(\mathbf{X})=0.5$ and above which signals are classified as freight vibration signals. With this fit of the regression model to the data, four passenger railway signals and four freight railway signals exist in the wrong prediction regions and would be incorrectly classified if introduced to the model as unlabeled signals. However, the remaining 190 passenger railway signals and 40 freight railway signals exist in the correct region and would be correctly classified. This is commensurate with the reported 96\% accuracy of the model. Most passenger railway vibration signals are clustered together in a region of low event duration and low proportional $5 \mathrm{~Hz} 1 / 3 \mathrm{rd}$ octave band

TABLE I. Parameter estimates and other details of logistic regression

\begin{tabular}{|c|c|c|c|c|c|}
\hline \multirow{2}{*}{$\frac{\text { Parameter }}{\text { Intercept }}$} & \multirow{2}{*}{$\begin{array}{l}\theta \text { estimate } \\
-10.73\end{array}$} & \multirow{2}{*}{$\begin{array}{l}\begin{array}{c}\text { Standard } \\
\text { error }\end{array} \\
1.76\end{array}$} & \multirow{2}{*}{$\frac{p \text { value }}{<0.001}$} & \multicolumn{2}{|c|}{$\begin{array}{c}\text { Overall } \\
\text { model }\end{array}$} \\
\hline & & & & $N$ & 238 \\
\hline$T$ & 5.01 & 0.89 & $<0.001$ & $p$ value & $<0.001$ \\
\hline$F$ & 2.25 & 0.70 & $<0.010$ & $\begin{array}{l}\text { McFadden's } \\
\text { pseudo- } R^{2}\end{array}$ & 0.79 \\
\hline
\end{tabular}
model. 


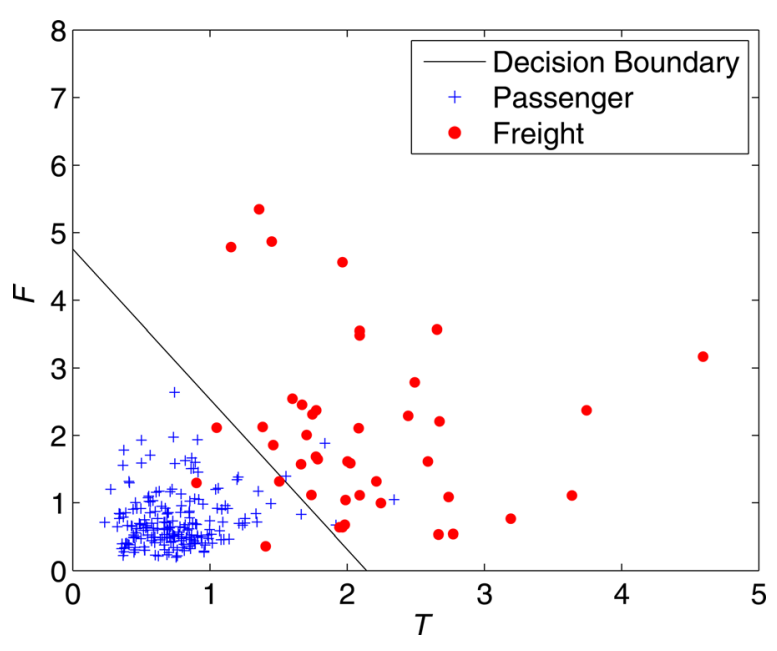

FIG. 1. (Color online) Decision boundary of logistic regression model as a function of the normalized signal event duration $(T)$ and normalized proportional $5 \mathrm{~Hz} 1 / 3 \mathrm{rd}$ octave band rms acceleration $(F)$.

energy. The freight railway vibration signals show more variation, but tend to have longer event durations and greater proportional energy in the $5 \mathrm{~Hz} 1 / 3$ rd octave band, allowing these signals to be separated with a certain degree of confidence using only these two signal properties.

\section{Determination of response}

Human responses, in terms of annoyance caused by freight and passenger railway vibration, were taken from questionnaire data collected during the field study. The particular question of interest for this research was: "Thinking about the last 12 months or so, how bothered, annoyed or disturbed have you been by vibration or feeling things rattle, vibrate or shake caused by [source]." Responses were recorded on 5 point semantic scales ("not at all," "slightly," "moderately," "very," and "extremely") and 11 point numeric scales (0-10) as recommended by Fields et al. (2001) and ISO/TS 15666 (International Organization for Standardization, 2003). For this work, the responses of the above question, where the source is either freight or passenger railway and the responses were recorded on a 5 point semantic scale, were collected for each respondent to quantify their annoyance response to freight and passenger railway vibration. Respondents who reported they had not felt any vibration or shaking that they thought was caused by the railway had their annoyance responses recoded to the lowest category on the semantic scale.

\section{Development of exposure-response relationships}

By applying the logistic regression model to vibration exposure measurements, vibration exposures were determined as $W_{k}$ weighted rms acceleration over all freight and passenger event pass-bys in a $24 \mathrm{~h}$ period for each of the 752 residents. Exposure-response relationships were then determined using an ordinal probit model with fixed thresholds, based on a model presented by Groothuis-Oudshoorn and Miedema (2006) who used the model to develop similar exposure-response relationships for environmental noise.
The resulting exposure-response relationship takes the form of a curve indicating the percentage of people that are likely to express annoyance above a certain threshold $(C)$ for a given vibration exposure $(V)$,

$$
p(V)=100\left(1-\Phi\left[\frac{C-\mathbf{V} \boldsymbol{\beta}}{\sigma}\right]\right),
$$

where $\Phi$ represents the cumulative normal distribution function, $\mathbf{V}$ is a vector of vibration exposures, $\boldsymbol{\beta}$ is a vector of model parameters to be estimated, and $\sigma$ is the standard error. The distribution of responses at different annoyance levels can be expressed by altering the threshold $C$. Three commonly used thresholds are $C=28$ (percent slightly annoyed), $C=50$ (percent annoyed), and $C=72$ (percent highly annoyed) (Groothuis-Oudshoorn and Miedema, 2006; Miedema and Oudshoorn, 2001). The model parameters can be estimated via maximum likelihood, with the following likelihood function:

$$
L(\boldsymbol{\beta})=\prod_{j=1} \prod_{y_{i}=j}\left[\Phi\left(\tau_{j}-\mathbf{v}_{i} \boldsymbol{\beta}\right)-\Phi\left(\tau_{j-1}-\mathbf{v}_{i} \boldsymbol{\beta}\right)\right],
$$

where $\tau_{j}$ is the cutpoint of the $j$ th category, derived from the five point semantic scale and $\mathbf{v}_{i}$ is a vector of exposures that result in response $y_{i}$. The $95 \%$ confidence intervals can be determined as a function of exposure $V$ as follows:

$$
C_{95}(V)=\mathbf{V} \boldsymbol{\beta} \pm Z \sqrt{\mathbf{V E}_{b} \mathbf{V}^{T}}
$$

where $\mathbf{E}_{b}$ is the covariance matrix of the $\boldsymbol{\beta}$ parameters and $Z=1.96$ for a standard normal distribution.

\section{EXPOSURE-RESPONSE RELATIONSHIPS}

To test the suitability of deriving separate exposureresponse relationships for freight and passenger vibration sources, an exposure-response relationship was derived for exposures and responses to both sources, with a dummy variable for source type ( 0 for passenger and 1 for freight). The fitting of this exposure-response relationship resulted in a highly significant parameter estimate for the source dummy variable $(p<0.001)$ and a significant increase in the likelihood $(p<0.001)$ when compared with the model without the dummy variable. This gives confidence that the difference in annoyance response is not just due to the strength of the vibration, and that it is justifiable to derive separate exposure-response relationships for freight and passenger sources. Parameter estimates and other details of the model with the dummy variable are shown in Table II.

Figure 2 shows exposure-response relationships for different degrees of annoyance caused by vibration from freight and passenger railway vibration. For comparison, the curves for percentage high annoyance for both freight and passenger railway vibration exposure are presented together in Fig. 3. Parameter estimates and other model details are presented in Table III. The exposure-response relationships show that freight railway vibration results in a greater annoyance response, even for equal levels of vibration exposure. 
TABLE II. Parameter estimates and other details of the ordinal probit model with a dummy source variable.

\begin{tabular}{|c|c|c|c|c|c|}
\hline \multirow{2}{*}{$\begin{array}{l}\text { Parameter } \\
\text { Intercept }\end{array}$} & \multirow{2}{*}{$\frac{\beta \text { estimate }}{41.22}$} & \multirow{2}{*}{$\begin{array}{c}\begin{array}{c}\text { Standard } \\
\text { error }\end{array} \\
12.15\end{array}$} & \multirow{2}{*}{$\frac{p \text { value }}{<0.001}$} & \multicolumn{2}{|c|}{$\begin{array}{c}\text { Overall } \\
\text { model }\end{array}$} \\
\hline & & & & $N$ & 1504 \\
\hline $10 \log \left(\mathrm{rms}_{k, 24 \mathrm{~h}}\right)$ & 2.47 & 0.46 & $<0.001$ & $p$ value & $<0.001$ \\
\hline $\begin{array}{l}\text { Source } \\
\text { dummy }\end{array}$ & 15.81 & 3.57 & $<0.001$ & $\begin{array}{l}\text { McFadden's } \\
\text { pseudo- } R^{2}\end{array}$ & 0.02 \\
\hline$\sigma$ & 52.24 & 2.28 & $<0.001$ & & \\
\hline
\end{tabular}

For example, for a $24 \mathrm{~h} \mathrm{rms}_{k}$ vibration exposure of $0.01 \mathrm{~m} \mathrm{~s}^{-2}$, approximately $4 \%$ of the studied population is likely to be highly annoyed if the source is passenger railway, whereas approximately $13 \%$ of the studied population is likely to be highly annoyed if the source is freight railway. In terms of equal annoyance response, $0.0100 \mathrm{~m} \mathrm{~s}^{-2}$ of passenger railway vibration exposure is equivalent to only $0.0007 \mathrm{~m} \mathrm{~s}^{-2}$ of freight railway vibration.

Fidell et al. (2011) provide a method of quantifying differences in community response to different noise sources using a community tolerance level (CTL). They define the CTL as the noise level at which $50 \%$ of a community
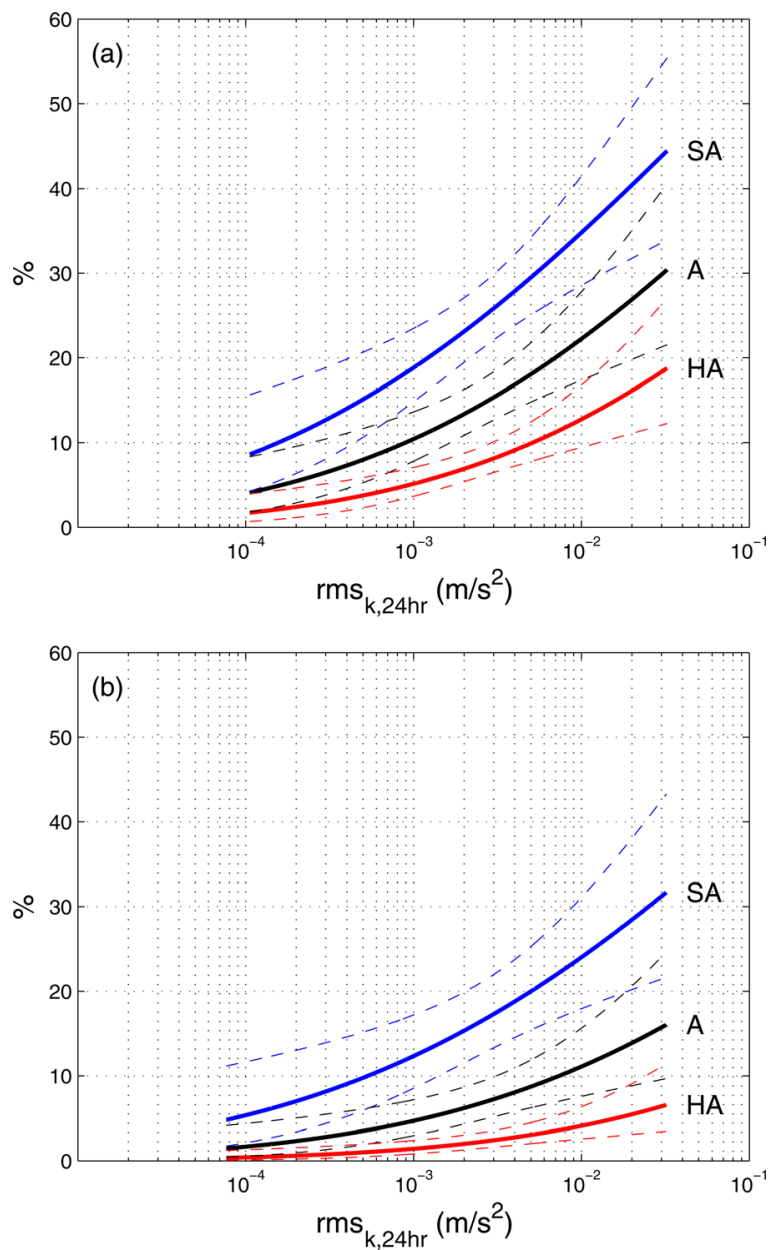

FIG. 2. (Color online) Exposure-response relationships showing percentage of slight annoyance (SA), annoyance (A), and high annoyance (HA) as a result of exposure to (a) freight railway vibration and (b) passenger railway vibration. $95 \%$ confidence intervals are indicated by broken lines.

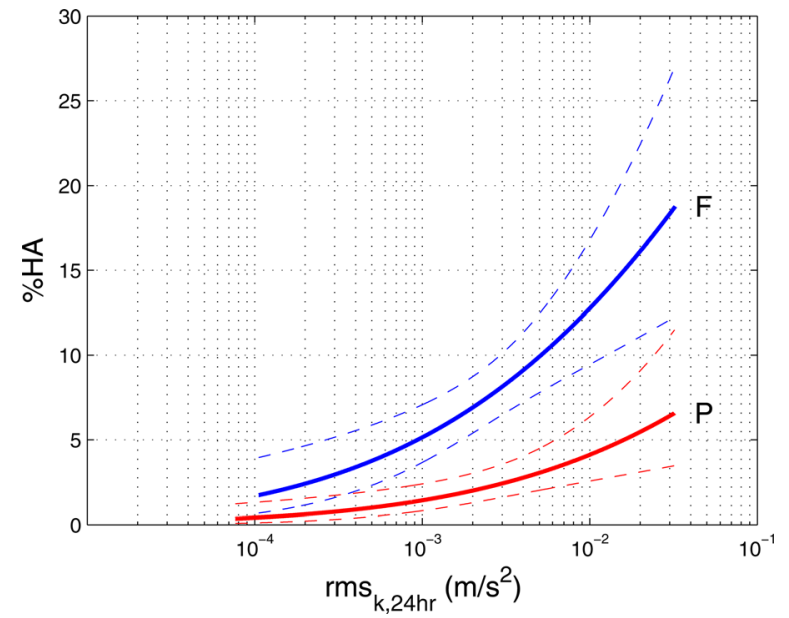

FIG. 3. (Color online) Exposure-response relationships showing the percentage of high annoyance (\%HA) caused by exposure to freight $(\mathrm{F})$ and passenger $(\mathrm{P})$ railway vibration, with the $95 \%$ confidence intervals indicated by broken lines.

population describe themselves as highly annoyed. Applying this method to vibration levels results in a CTL level of $78 \mathrm{~dB}$ for passenger railway vibration and $63 \mathrm{~dB}$ for freight railway vibration (re $10^{-6} \mathrm{~m} \mathrm{~s}^{-2}$ ). In other words, the population studied appears to be $15 \mathrm{~dB}$ more tolerant to passenger railway vibration than they are to freight railway vibration.

\section{DISCUSSION}

Exposure-response relationships presented in this paper suggest that the human response to freight railway vibration is significantly different from that due to passenger railway vibration, even for equal levels of vibration exposure. The difference in the responses suggest that people are able to differentiate between these two sources of railway vibration, and that freight railway vibration is significantly more annoying than passenger railway vibration.

Though no previous research has specifically investigated the differences in human response to different sources of railway vibration, previous field studies have reported differences in response to different sources of railway noise. In Fields and Walker's (1982) field study, freight trains were specifically mentioned as being most bothersome approximately three times more often than passenger trains. Similarly, more than half of the interviewees from a field study by Andersen et al. (1983) mentioned freight trains as being particularly disturbing. In their field study, Pennig et al. (2012) found that the annoyance response due to railway noise increased significantly with increasing total number of trains and number of freight trains but not with increasing number of passenger trains. Freight railway noise has also been shown to have a greater effect on sleep disturbance than passenger railway noise (Saremi et al., 2008) and even aircraft noise in some cases (Elmenhorst et al., 2012). These studies suggest a difference in the human response to different sources of railway noise, so it is not a surprising result that differences also exist between sources of railway vibration. In terms of both noise and vibration, it appears that freight railway traffic is more annoying than 
TABLE III. Parameter estimates and other details of the ordinal probit model for freight and passenger railway sources.

\begin{tabular}{|c|c|c|c|c|c|}
\hline \multicolumn{6}{|c|}{ Freight } \\
\hline Parameter & $\beta$ estimate & Standard error & $p$ value & \multicolumn{2}{|c|}{ Overall model } \\
\hline Intercept & 63.06 & 18.29 & $<0.001$ & $N$ & 752 \\
\hline $10 \log \left(\mathrm{rms}_{k, 24 \mathrm{~h}}\right)$ & 2.90 & 0.70 & $<0.001$ & $p$ value & $<0.001$ \\
\hline$\sigma$ & 58.90 & 3.19 & $<0.001$ & McFadden's pseudo- $R^{2}$ & 0.01 \\
\hline \multicolumn{6}{|c|}{ Passenger } \\
\hline Parameter & $\beta$ estimate & Standard error & $p$ value & \multicolumn{2}{|c|}{ Overall model } \\
\hline Intercept & 36.52 & 14.37 & $<0.050$ & $N$ & 752 \\
\hline $10 \log \left(\mathrm{rms}_{k, 24 \mathrm{~h}}\right)$ & 1.93 & 0.56 & $<0.001$ & $p$ value & $<0.010$ \\
\hline$\sigma$ & 42.66 & 3.09 & $<0.001$ & McFadden's pseudo- $R^{2}$ & 0.01 \\
\hline
\end{tabular}

passenger railway traffic. Although this paper has demonstrated that this is true even for equal levels of vibration exposure, previous research has shown that the same may not be true for equal levels of noise exposure (de Jong and Miedema, 1996).

Differences in response to freight and passenger railway noise are often attributed to the increased duration of freight pass-bys and the greater proportion of low frequency noise (Pennig et al., 2012). Similar conclusions can be drawn about differences between freight and passenger railway vibration. Indeed, it has been shown that the logistic regression model can accurately distinguish between freight and passenger railway vibration signals based only on their duration and low frequency energy content. In this work, the mean duration of freight vibration events is $23.8 \mathrm{~s}(\mathrm{SD}=5.4)$ and the mean duration of passenger vibration events is $16.1 \mathrm{~s}$ $(\mathrm{SD}=6.4)$. As well as being longer in duration, freight trains are typically heavier and can more easily elicit ground-borne vibrations (de Jong, 1979). BS 6472-1 (British Standards Institution, 2008) defines a region of high sensitivity for humans for vertical vibration from 4 to $12.5 \mathrm{~Hz}$. For this study the mean proportion of a signal's energy that is contained within this region is $18.4 \%$ for freight signals $(\mathrm{SD}=12.4)$, and $14.4 \%(\mathrm{SD}=9.5)$ for passenger signals.

An additional factor may be found in the tendency of freight railway traffic to be more frequent during evening and night time hours. In this work the mean proportion of freight traffic during day time hours (07:00 to 19:00) evening time hours (19:00 to 23:00) and night time hours $(23: 00$ to
$07: 00)$ is $10.1,18.2$, and $21.5 \%$, respectively $(\mathrm{SD}=4.7$, 12.0, 11.6). Peris et al. (2012) demonstrated that annoyance due to equal levels of railway vibration exposure is greater during night time than during evening time, and greater during evening time than during day time. The fact that freight traffic is more prevalent during periods in which sensitivity to railway vibration is higher is therefore likely to affect the annoyance response to freight railway vibration.

The British Standard BS 6472-1 (British Standards Institution, 2008) provides limited guidance in the form of ranges of vibration dose value that may result in various probabilities of adverse comment within residential buildings. Table IV relates these guideline values of vibration exposure to predicted proportions of high annoyance for exposure to equivalent $24 \mathrm{~h}$ freight and passenger railway vibration exposures. The predicted proportions of high annoyance are taken from exposure-response relationships derived in the same way as described in Sec. II, but with vibration exposure quantified by vibration dose value (VDV), instead of rms acceleration. Equivalent $24 \mathrm{~h}$ exposures are used for comparison as source specific responses are only available over a full $24 \mathrm{~h}$ period in the questionnaire data. This table suggests that the guidelines may potentially underestimate human response by considering a single limit for all sources of environmental vibration (other than blasting). For example, a guideline value of up to $0.4 \mathrm{~m} \mathrm{~s}^{-1.75}$ allows freight vibration exposures that may cause up to $18 \%$ of the studied population to be highly annoyed, which is likely to cause more than the "low probability of adverse

TABLE IV. Comparison of guideline values as proposed by BS 6472-1 (British Standards Institution, 2008) to equivalent predicted proportion of high annoyance caused by equivalent levels of $24 \mathrm{~h}$ freight and passenger railway vibration exposure.

\begin{tabular}{|c|c|c|c|}
\hline & & Residential buildings $16 \mathrm{~h}$ day & Residential buildings $8 \mathrm{~h}$ night \\
\hline \multirow[t]{3}{*}{ Low probability of adverse comment } & Guideline range (VDV, $\mathrm{m} \mathrm{s}^{-1.75}$ ) & $0.2-0.4$ & $0.1-0.2$ \\
\hline & $\% \mathrm{HA}$ by equivalent $24 \mathrm{~h}$ freight exposure & $15-18$ & $12-15$ \\
\hline & $\% \mathrm{HA}$ by equivalent $24 \mathrm{~h}$ passenger exposure & $5-7$ & $4-5$ \\
\hline \multirow[t]{3}{*}{ Adverse comment possible } & Guideline range (VDV, $\mathrm{m} \mathrm{s}^{-1.75}$ ) & $0.4-0.8$ & $0.2-0.4$ \\
\hline & $\% \mathrm{HA}$ by equivalent $24 \mathrm{~h}$ freight exposure & 18 to $>21^{\mathrm{a}}$ & $15-18$ \\
\hline & $\% \mathrm{HA}$ by equivalent $24 \mathrm{~h}$ passenger exposure & $>7^{\mathrm{a}}$ & $5-7$ \\
\hline \multirow[t]{3}{*}{ Adverse comment probable } & Guideline range (VDV, $\mathrm{m} \mathrm{s}^{-1.75}$ ) & $0.8-1.6$ & $0.4-1.8$ \\
\hline & $\%$ HA by equivalent $24 \mathrm{~h}$ freight exposure & $>21^{\mathrm{a}}$ & 18 to $>21$ \\
\hline & $\% \mathrm{HA}$ by equivalent $24 \mathrm{~h}$ passenger exposure & $>7^{\mathrm{a}}$ & $>7^{\mathrm{a}}$ \\
\hline
\end{tabular}

${ }^{a}$ Outside range of measured exposures. 
comment" suggested by the guidelines. In contrast, equivalent levels of passenger vibration exposures may cause up to $7 \%$ of the studied population to be highly annoyed, which is perhaps more commensurate to "low probability of adverse comment." There are several other guidelines for environmental vibration that are used nationally and internationally, covering a wide range of levels and exposure descriptors, none of which provide different guidance levels for different sources of railway vibration. The disparate responses caused by equal levels of freight and passenger railway vibration exposure, however, suggest that it is necessary to consider different guideline levels for different sources of railway vibration.

A limitation of the current work is that the exposureresponse relationships are derived for exposure to railway vibration only, with no consideration for combined noise effects. Many studies have shown that vibration can influence the annoyance response to noise and vice versa and that combined noise and vibration influences the general annoyance response (Gidlöf-Gunnarsson et al., 2012; Howarth and Griffin, 1990, 1991; Lercher, 2011; Öhrström, 1997; Paulsen and Kastka, 1995). During the field study performed by Waddington et al. (2014), exposure-response relationships were determined for exposure to combined railway noise and vibration (Woodcock et al., 2011). The noise exposures were estimated by Koziel et al. (2011) and were based on several assumptions about the railway traffic, including the proportion of freight traffic. With the number of freight and passenger trains now determined for each case study, future work could involve updating estimations of noise exposures and determining subsequent exposure-response relationships for exposure to combined railway noise and vibration for all sources and for freight and passenger railway separately.

\section{v. CONCLUSIONS}

Ordinal probit analysis with a source dummy variable has indicated that deriving separate exposure-response relationships for freight and passenger railway vibration is valid. Exposure-response relationships have thus been developed for annoyance caused by vibration from freight and passenger railway traffic. The differences between these relationships indicate that people are able to differentiate between these two sources of railway vibration, and that freight railway vibration is significantly more annoying than passenger railway vibration, even for equal levels of vibration exposure. In terms of a community tolerance level, the population studied appears to be $15 \mathrm{~dB}$ (re $10^{-6} \mathrm{~m} \mathrm{~s}^{-2}$ ) more tolerant to passenger railway vibration than to freight railway vibration. These results could have important implications for the expansion of freight traffic on rail, or for policy that aims to promote passenger railway. The differences in response suggest that guidelines and policies need to consider these sources separately in order to control the annoyance response of the operation and expansion of railway lines.

\section{ACKNOWLEDGMENTS}

Data for this research come primarily from the field study performed by Waddington et al. (2014) and funded by the Department for Environment, Food and Rural Affairs (Defra, UK). The survey data were collected under the supervision of A. Steele of the Salford Housing and Urban Studies Unit (SHUSU).

Andersen, T. V., Kühl, K., and Relster, E. (1983). "Reactions to railway noise in Denmark," J. Sound Vib. 87, 311-314.

British Standards Institution (2008). BS 6472-1, Guide to Evaluation of Human Exposure to Vibration in Buildings. Part 1: Vibration Sources Other than Blasting (British Standards Institution, London).

Commission of the European Communities (2001). "White Paper-European transport policy for 2010: Time to decide," Brussels, http://ec.europa. eu/ transport/themes/strategies/2001_white_paper_en.htm (Last viewed 03/04/13).

Elmenhorst, E.-M., Pennig, S., Rolny, V., Quehl, J., Mueller, U., Maaß, H., and Basner, M. (2012). "Examining nocturnal railway noise and aircraft noise in the field: Sleep, psychomotor performance, and annoyance," Sci. Total Environ. 424, 48-56.

Fidell, S., Mestre, V., Schomer, P., Berry, B., Gjestland, T., Vallet, M., and Reid, T. (2011). "A first-principles model for estimating the prevalence of annoyance with aircraft noise exposure," J. Acoust. Soc. Am. 130, 791-806.

Fields, J. M. (1979). "Railway noise and vibration annoyance in residential areas," J. Sound Vib. 66, 445-458.

Fields, J. M., de Jong, R. G., Gjestland, T., Flindell, I. H., Job, R. F. S., Kurra, S., Lercher, P., Vallet, M., Yano, T., Guski, R., Felscher-Suhr, U., and Schumer, R. (2001). "Standardized general-purpose noise reaction questions for community noise surveys: Research and a recommendation," J. Sound Vib. 242, 641-679.

Fields, J. M., and Walker, J. G. (1982). "The response to railway noise in residential areas in Great Britain,” J. Sound Vib. 85, 177-255.

Gidlöf-Gunnarsson, A., Ögren, M., Jerson, T., and Öhrström, E. (2012). "Railway noise annoyance and the importance of number of trains, ground vibration, and building situational factors," Noise Health 14, 190-201.

Groothuis-Oudshoorn, C. G. M., and Miedema, H. M. E. (2006). "Multilevel grouped regression for analyzing self-reported health in relation to environmental factors: the model and its application," Biometrical J. 48, 67-82.

Howarth, H. V. C., and Griffin, M. J. (1990). "Subjective response to combined noise and vibration: Summation and interaction effects," J. Sound Vib. 143, 443-454.

Howarth, H. V. C., and Griffin, M. J. (1991). "The annoyance caused by simultaneous noise and vibration from railways," J. Acoust. Soc. Am. 89, 2317-2323.

International Organization for Standardization (1997). ISO 2631-1, Mechanical Vibration and Shock-Evaluation of Human Exposure to Whole-Body Vibration-Part 1: General Requirements (International Organization for Standardization, Geneva, Switzerland).

International Organization for Standardization (2003). ISO/TS15666, Acoustics-Assessment of Noise Annoyance by Means of Social and SocioAcoustic Surveys (International Organization for Standardization, Geneva, Switzerland).

de Jong, R. G. (1979). "A Dutch study on railroad traffic noise," J. Sound Vib. 66, 497-502.

de Jong, R. G., and Miedema, H. M. E. (1996). "Is freight traffic noise more annoying than passenger traffic noise?" J. Sound Vib. 193, 35-38.

Klæboe, R., Turunen-Rise, I. H., Harvik, L., and Madshus, C. (2003). "Vibration in dwellings from road and rail traffic-Part II: Exposureeffect relationships based on ordinal logit and logistic regression models," Appl. Acoust. 64, 89-109.

Knall, V. (1996). "Railway noise and vibration: effects and criteria," J. Sound Vib. 193, 9-20.

Koziel, Z., Smith, M. G., Woodcock, J., Peris, E., Sica, G., Moorhouse, A. T., and Waddington, D. C. (2011). "Human response to vibration in residential environments (NANR209), technical report 4: Calculation of noise exposure," Defra, London, http://usir.salford.ac.uk/23387/ (Last viewed 03/04/13).

Lee, P. J., and Griffin, M. J. (2013). "Combined effect of noise and vibration produced by high-speed trains on annoyance in buildings," J. Acoust. Soc. Am. 133, 2126-2135.

Lercher, P. (2011). "Combined noise exposure at home," in Encyclopedia of Environmental Health, edited by J. Nriagu (Elsevier, Amsterdam), 
http://literati.credoreference.com/content/entry/estenvh/combined_noise exposure_at_home/0 (Last viewed 03/04/13)

Miedema, H. M. E., and Oudshoorn, C. G. M. (2001). "Annoyance from transportation noise: relationships with exposure metrics DNL and DENL and their confidence intervals," Environ. Health Persp. 109, 409-416.

Miedema, H. M. E., and Vos, H. (1998). "Exposure-response relationships for transportation noise," J. Acoust. Soc. Am. 104, 3432-3445.

Moehler, U. (1988). "Community response to railway noise: A review of social surveys," J. Sound Vib. 120, 321-332.

Moehler, U., Liepert, M., Schuemer, R., and Griefahn, B. (2000). "Differences between railway and road traffic noise," J. Sound Vib. 231, 853-864.

Öhrström, E. (1997). "Effects of exposure to railway noise-A comparison between areas with and without vibration," J. Sound Vib. 205, $555-560$.

Paulsen, R., and Kastka, J. (1995). "Effects of combined noise and vibration on annoyance," J. Sound Vib. 181, 295-314.

Pennig, S., Quehl, J., Mueller, U., Rolny, V., Maass, H., Basner, M., and Elmenhorst, E. (2012). "Annoyance and self-reported sleep disturbance due to night-time railway noise examined in the field," J. Acoust. Soc. Am. 132, 3109-3117.

Peris, E., Woodcock, J., Sica, G., Moorhouse, A. T., and Waddington, D. C. (2012). "Annoyance due to railway vibration at different times of the day,” J. Acoust. Soc. Am. 131, EL191-EL196.
Saremi, M., Grenèche, J., Bonnefond, A., Rohmer, O., Eschenlauer, A., and Tassi, P. (2008). "Effects of nocturnal railway noise on sleep fragmentation in young and middle-aged subjects as a function of type of train and sound level," Int. J. Psychophysiol. 70, 184-191.

Schomer, P., Mestre, V., Fidell, S., Berry, B., Gjestland, T., Vallet, M., and Reid, T. (2012). "Role of community tolerance level (CTL) in predicting the prevalence of the annoyance of road and rail noise," J. Acoust. Soc. Am. 131, 2772-2786.

Waddington, D. C., Woodcock, J., Peris, E., Condie, J., Sica, G., Moorhouse, A. T., and Steele, A. (2014). "Human response to vibration in residential environments," J. Acoust. Soc. Am. 135, 182-193.

Wiebe, E., Sandor, J., Cheron, C., and Haas, S. (2011). "ERRAC roadmap-WP 01-The greening of surface transport. Towards 2030-Noise and vibrations roadmap for the European railway sector," Paris, Brussels, http://www.errac.org/IMG/pdf/errac_wp01_roadmap_noise_and_vibration_ v06-2.pdf (Last viewed 03/04/13).

Woodcock, J., Peris, E., Condie, J., Sica, G., Koziel, Z., Evans, T., Moorhouse, A. T., Steele, A., and Waddington, D. C. (2011). "Human response to vibration in residential environments (NANR209), Technical report 6: Determination of exposure-response relationships," Defra, London, http://usir.salford.ac.uk/23386/ (Last viewed 03/04/13).

Zapfe, J. A., Saurenman, H., and Fidell, S. (2009). "Ground-borne noise and vibration in buildings caused by rail transit," Transport Cooperative Research Program, http://www.trb.org/Publications/Blurbs/163649.aspx (Last viewed 03/04/13). 